\title{
As representações históricas e constitutivas de Internacional e Grêmio no futebol gaúcho e seus enredos sociais
}

The historical and constitutive representations of International and Gremio in football of Rio Grande do Sul (Brazil) and their social aspects

Las representaciones históricas y constitutivas de Internacional y Gremio en el fútbol de Rio Grande do Sul(Brasil) y sus enredos sociales

Vinícius Triches $^{\mathrm{I}}$, Ancilla Dall’onder Zat ${ }^{\mathrm{II}}$

\begin{abstract}
Resumo
O futebol, enquanto desporto de relevância social inconteste, tem permeado diferentes interpretações sobre as relações que acaba por gerar, estando entre estas as representações que definem aspectos importantes no imaginário popular. Com base em uma pesquisa exploratória e bibliográfica, no presente trabalho, buscouse perceber as representações históricas e constitutivas no contexto do futebol gaúcho, tendo como atores principais os seus principais clubes (Grêmio e Internacional). Percebeu-se que as representações relacionadas às origens dos clubes, de acordo com as classes sociais envolvidas e com as formas de jogar futebol adotadas consolidaram o imaginário dos torcedores dos clubes, reforçando sua rivalidade entre e vivenciando aspectos a serem sempre retomados, apesar de que atualmente possam ser questionados com base em novas evidências.
\end{abstract}

Palavras-chave: Futebol; Representações; Sociedade; Torcedor

\begin{abstract}
Football, as a sport of undisputed social relevance, it has permeated different interpretations of the relationships it ends up generating, among which are the representations that define important aspects in the popular imagination. Based on an exploratory and bibliographic research, in this work, we sought to understand the historical and constitutive representations in the context of football in Rio Grande do Sul (Brazil), considering as mean actors the main clubs (Gremio and Internacional). It was noticed that the representations related to the origins of the clubs, according to the social classes involved and the ways of playing football adopted, consolidated the imaginary of the fans of the clubs, reinforcing their rivalry between them and experiencing aspects to always be taken up, despite of the fact that currently can be questioned based on new evidences.
\end{abstract}

Keywords: Football; Representations; Society; Fan

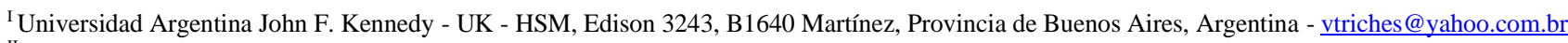

${ }^{\text {II }}$ Faculdade da Serra Gaúcha - FSG - ancila@italnet.com.br 


\section{Resumen}

El fútbol, como deporte de indiscutible relevancia social, ha permeado distintas interpretaciones de las relaciones que acaba generando, entre las que se encuentran las representaciones que definen aspectos importantes en el imaginario popular. A partir de una investigación exploratoria y bibliográfica, en este trabajo se buscó comprender las representaciones históricas y constitutivas en el contexto del fútbol en Rio Grande do Sul (Brasil), con los principales clubes (Gremio e Internacional) como actores principales. Se notó que las representaciones relacionadas con los orígenes de los clubes, según las clases sociales involucradas y las formas de jugar al fútbol adoptadas, consolidaron el imaginario de los aficionados de los clubes, reforzando su rivalidad y vivenciando aspectos a ser siempre asumidos, aunque actualmente se puede cuestionar en base a nuevas evidencias.

Palabras clave: Fútbol; Representaciones; La sociedad; Hincha

\section{Introdução: Contextualização da problemática e elementos propícios à investigação}

O futebol é um ambiente clássico para a formatação de representações que permeiam historicamente o imaginário popular no Brasil, movimento esse sempre reprisado, segundo as conveniências momentâneas dos torcedores. É nesse sentido que as rivalidades clubísticas são elementos importantes da propagação e reprodução de determinadas características e ritos associados aos clubes de futebol, normalmente ancoradas em conotações que visam lembrar algum aspecto particular histórico. É dessa forma que Da Matta et al. (1982, p.21) destacam o futebol praticado, vivido, discutido e teorizado no Brasil: "[...] seria um modo específico, entre tantos outros, pelo qual a sociedade brasileira fala, apresenta-se, revela-se, deixando-se, portanto, descobrir".

Tais recordações têm, em linhas gerais, associações com um fato ou um evento acontecido durante os anos iniciais do seu clube ou do rival e, algumas vezes, também com algum episódio posterior, como um enfrentamento particular, um campeonato conquistado ou perdido e até a construção de um estádio. O contexto de formação e consolidação dos principais clubes de futebol do Rio Grande do Sul é diversificado nesse sentido. De acordo com Damo (2002a), por mais que alguns elementos tenham cerca de um século de sua ocorrência, ainda despertam debates e conflitos entre as torcidas.

Cabe, nesse sentido, destacar duas representações históricas e constitutivas de caráter coletivo do Sport Club Internacional e do Grêmio Foot-Ball Porto Alegrense, de maneira a pinçar elementos que podem destacar aspectos interessantes para o entendimento de características norteadoras do imaginário popular. De forma mais direta, atributos do próprio torcedor colorado ou gremista, visto que, segundo Franco Jr. (2007), a marca qualitativa de um clube desperta fortes sentimentos alheios, um desafio à própria identidade. 
Tal discussão é importante para a compreensão das identidades clubísticas de Internacional e Grêmio, dado que a questão do outro é sempre importante na relação entre os clubes citados. Como o Rio Grande do Sul é um estado que conta com apenas dois grandes clubes, a rivalidade apresenta-se de forma mais aguda, não tendo aspecto da vida social que escape ao maniqueísmo tricolor ou colorado, ainda segundo Franco Jr. (2007). Assim, o objetivo principal do presente trabalho é destacar as representações constitutivas e históricas de Grêmio e Internacional no contexto do futebol gaúcho e os enredos sociais formados, tendo como base a rivalidade clubística.

Para tanto, o presente estudo se divide em seis partes, a primeira contempla a introdução e a segunda os principais procedimentos metodológicos adotados. A terceira parte tem como meta apresentar a noção de representação, de acordo com os seus significados e questionamentos. A quarta apresenta uma discussão sobre os chamados "clubes populares" versus "clubes de elites", versão rotineira que caracterizou as primeiras décadas das agremiações esportivas estudadas e é objeto de menções até os dias atuais. Já a quinta parte relata o contexto da formação e consolidação dos clubes de acordo com as formas de pensar e jogar o futebol, sendo estas representadas pelas escolas do "futebol- força" e do "futebol-arte". Por fim, a sexta e última parte apresenta as principais conclusões.

\section{Procedimentos metodológicos}

Para alcançar o objetivo do presente trabalho, realizou-se pesquisa exploratória, de acordo com o alcance de desenho, e pesquisa bibliográfica, quanto aos procedimentos técnicos adotados. Gil (2014) menciona que uma pesquisa bibliográfica é aquela desenvolvida a partir de material já elaborado, principalmente artigos científicos e livros. Já a pesquisa exploratória, segundo Biagi (2012), normalmente é escolhida quando se trata de estudos preliminares, sobre assuntos pouco sistematizados, cuja conveniência é “[...] usar esse desenho quando se está buscando indícios de um problema [...]” (BIAGI, 2012, p. 54).

Foram consultadas bibliografias da literatura recente sobre o conceito da representação na Psicologia, bem como de elementos culturais e históricos do futebol com foco na constituição da rivalidade entre Internacional e Grêmio. Adotou-se, assim, a leitura e análise de artigos científicos, trabalhos de conclusão e livros sobre as temáticas, buscando o confronto entre as diferentes perspectivas, de acordo com os autores selecionados. 


\section{Representação: significados e questionamentos}

Sobre o termo "representação", de uso corrente na Psicologia, segundo Blanc (2006) apud Deschamps e Moliner (2014), há pelo menos dois significados que devem ser retomados, visando uma melhor compreensão de seu caráter.

O primeiro significado remete "[...] à ação de tornar presente alguma coisa ausente; o segundo remete à ideia de substituição, isto é, a representação substitui seu objeto" (DESCHAMPS e MOLINER, 2014, p. 80). O uso dos dois significados evoca, ao mesmo tempo, um processo dinâmico de "tornar presente", "substituir" e também a percepção do agente ou suporte desse processo. Os autores destacam que a partir dos dois significados podem ser visualizadas numerosas formas de representação.

Já Woodward (2014) entende que a representação inclui as práticas de significação e os sistemas simbólicos por meio dos quais os significados são produzidos e, logo após, posicionados como sujeitos. Os significados, produzidos pelas representações, oferecem sentido a nossa experiência e a tudo aquilo que somos.

A representação, tida como um processo cultural, estabelece identidades individuais e coletivas. Ela também constitui os sistemas simbólicos nos quais ela vai se basear para responder as possíveis respostas sobre questões como, ainda de acordo com o autor, quem somos, o que poderíamos ser e quem queremos ser.

Já Goffman (1985), em sua obra clássica “A representação do eu na vida cotidiana”, destaca que a representação deve ser entendida como toda atividade oriunda de um indivíduo. Essa atividade acontece em um período caracterizado por sua presença contínua diante de um grupo de observadores, exercendo sobre esses alguma influência. Nesse contexto, surge a acepção do termo "fachada", como "a dimensão do desempenho do indivíduo, que funciona regularmente de forma geral e fixa com o objetivo de definir a situação para os observadores de uma representação" (GOFFMAN, 1985, p. 29).

\section{Rio Grande dividido entre o "clube popular" e o "clube da elite": os primórdios e contextos da fundação da dupla Gre-Nal e as representações futebolísticas derivadas}

A investigação dos elementos históricos da criação dos clubes de futebol no Brasil e no mundo sempre foi permeada, em tom de curiosidade, pela discussão das variadas classes e origens sociais envolvidas nesse processo de construção. Nesse sentido, a noção de pertença, aos ditos clubes populares, 
ou pertencentes a colônias originárias, é sempre lembrada como questão de orgulho e ufanismo. Entretanto, deve-se lembrar de que tais elementos são normalmente resultantes do contexto econômico e político específico.

O Grêmio, primeiro grande rival do Fuss-Ball Porto Alegre (nascido também em 1903), disputa com esse clube o Troféu Wanderpreis em seus primeiros anos de vida, mas é o único desses a sobreviver e a se tornar um grande clube já nas décadas seguintes, segundo destaca Damo (2002b). A construção de sua identidade, enquanto clube de futebol, tem estreitos vínculos com os seus fundadores, de origem germânica, de acordo com Damo (2002b). Os teuto-brasileiros, que tinham uma tradição associacionista e que haviam tido uma rápida ascensão econômica nas décadas anteriores, foram elementos importantes para a difusão das práticas esportivas na segunda metade do século XIX em Porto Alegre. É dessa forma que:

\footnotetext{
Neste processo a intensa participação dos teuto-brasileiros demarca uma peculiaridade da formação urbana porto-alegrense. Em geral conservadores, ligados a elite econômica, os teuto-brasileiros deram aos clubes a ossatura administrativa e balizaram os parâmetros éticos e estéticos do gosto esportivo e futebolístico no Rio Grande do Sul. Tais especificidades devem ser consideradas quando se pensa questões envolvendo o estilo de jogo e a identidade nacional. (DAMO, 2002b, p. 65).
}

Ferla (2002), jornalista e torcedor do Grêmio, reforça a tese da influência alemã na criação do clube, apesar de lembrar que também participaram da sua fundação os imigrantes de origem portuguesa e italiana, mas em bem menor número. Percebe-se então a influência alemã no clube já em seus primeiros passos, como local escolhido para ser o seu primeiro lar (o ascendente bairro dos Moinhos de Vento), um reduto germânico na capital. Além disso, havia grande rigor estendido às obrigações de cada sócio, com a destituição de alguns logo após serem empossados, através de um rígido estatuto que colocava, entre outras obrigações, a necessidade de avisar ao clube quando o sócio se ausentaria de Porto Alegre.

Paralelamente exercem influência no período as concepções positivistas, originárias do pensamento do francês Augusto Comte (1978). O autor apregoava a explicação dos fenômenos naturais, assim como os sociais, provenientes de um só princípio, ou seja, por exemplo, a visão positiva dos fatos deveria buscar a pesquisa das suas leis, vistas como relações abstratas e constantes entre os fenômenos observáveis. Assim, há uma associação, desde cedo, com o chamado "estilo gaúcho de jogar futebol" ao futebol do Grêmio, tanto por este ser o precursor dos grandes clubes gaúchos que se mantiveram em atividade, quanto pela influência originária germânica e a concepção política vigente dos governantes estaduais do período, segundo Tosin (2008). 
Ainda de acordo com o autor, tal conjugação de fatores produz uma “[...] mentalidade elitista e segregadora e os ideais de pureza, família e tradição, tão próprias do pensamento positivista e também cultuados em movimentos de tradição gaúcha” (TOSIN, 2008, p. 27), ideias constantes nos primórdios de fundação do Grêmio. Dentro dessa perspectiva, Guazzelli (2010) lembra que as associações formadas por descendentes alemães eram tradicionalmente refratárias ao ingresso de pessoas que não tivessem a mesma origem que a sua.

Já o Internacional teria sido fundado “[...] apesar e contra os alemães e sua mentalidade elitista" (TOSIN, 2008, p. 34). Tal origem tem associação com seu próprio nome (“Internacional”), que dá sentido a uma política de associação a pessoas de diferentes origens e nacionalidades. É dessa forma que a ata de fundação do clube, no ano de 1909, foi assinada por dois negros, segundo Internacional (2020), o que se tornou elemento importante para mostrar que desde os seus primórdios o clube primava pela aceitação de integrantes de diferentes raças ou nacionalidades, de acordo com a mesma fonte.

Tal constatação é importante para entender, de acordo com Tosin (2008), também, o porquê de o clube ter sido o precursor da inclusão de atletas negros em suas equipes, ainda em 1926, sete anos antes da profissionalização do futebol no país. Essa tese é corroborada por Braga (2000), jornalista e torcedor colorado, ao destacar a participação e empenho popular ainda na fundação do Internacional, conforme pode ser visto a seguir:

\footnotetext{
Quando o dia 4 de abril de 1909 amanheceu em Porto Alegre, estudantes e comerciários, unidos pela mesma paixão, levantaram mais cedo do que recomendava a rotina de domingo. Afinal, um fato esportivo, marcado para a tarde daquele dia, mudaria o ânimo da cidade, aglutinando pessoas, revitalizando energias e deixando para trás boa parte do interesse da população pelos hipódromos, circos e velódromos: a fundação do Sport Club Internacional. (p. 15).
}

A tradição democrática e inclusiva do clube surgiu ainda no momento da escolha de suas cores, conforme o mesmo autor. Com a prevalência da vontade da maioria de seus fundadores ali presentes representados pelos Venezianos Carnavalescos -, que usavam a cor vermelha e branca e eram foliões da classe média, em detrimento das cores verde e branca, dos foliões da Sociedade Esmeralda, de caráter mais elitizado. Houve aceitação por parte dos foliões esmeraldinos da votação realizada, o que evocaria, desde o princípio, que "[...] divergências à parte, numa coisa todos concordavam: o Internacional jamais deveria se afastar de sua vocação povoeira, democrática e carnavalesca” (BRAGA, 2000, p. 17). 
Já Damo (2002a), ao mencionar os primeiros anos do Internacional e a proclamação do estigma "clube do povo", destaca que a agremiação não era aberta indiscriminadamente a qualquer adesão, embora, desde o princípio, os seus critérios de aceitação fossem menos rígidos que os aplicados pelo Grêmio. Foi dessa forma que, desde logo, pequenos comerciantes, comerciários, funcionários públicos e estudantes em geral, “[...] via de regra, ainda jovens e, portanto, em busca de afirmação social, compunham a base dos frequentadores do clube" (DAMO, 2002a, p. 68).

Em linha oposta à de Braga (2000) e de Damo (2002a), Gerchmann (2015), jornalista e torcedor do Grêmio, não vê maiores diferenças entre os fundadores de Internacional e Grêmio no que se referem as suas classes sociais, ao destacar que os pioneiros colorados e gremistas eram "[...] todos eles, brancos, em média por volta dos vinte anos. Predominavam comerciantes, comerciários, estudantes e funcionários públicos" (GERCHMANN, 2015, p. 25).

Relativamente à tese tradicional da inclusão dos negros ter ocorrido no Grêmio somente no ano de 1952, com a contratação do ex-atacante colorado Tesourinha, Gerchmann (2015) menciona que tal fato deu-se em função de ação afirmativa, quando o clube registrou, em seu estatuto, no ano de 1947, a proibição da discriminação de acordo com a cor de pele, etnia ou religião, mesmo que essa não fosse praticada. Para tanto, o autor destaca que o primeiro jogador inquestionavelmente negro a jogar na dupla Gre-Nal teria sido Adão Lima, que atuou pelo Grêmio entre os anos de 1925 e 1935.

Já para Damo (2002a) a criação do Internacional se deu de forma respeitosa em relação ao próprio Grêmio, em que este foi convidado para estrear oficialmente o novo clube, através de jogo realizado no mesmo ano. Sobre o primeiro clássico Gre-Nal, segundo Coimbra et al. (2009), os gremistas não concordaram que o clube desafiante bancasse os gastos do evento, fato que poderia onerar as receitas do novo clube.

É dessa maneira que Damo (2002a) destaca algumas interrogações sobre os variados mitos criados ao longo dos anos, normalmente associando o Grêmio, desde a sua origem, com um clube de uma elite segregadora, ao passo que o Internacional seria o clube popular desde os seus primórdios. Assim:

Em resumo, nem o Inter e muito menos o Grêmio foram forjados a partir da mobilização popular mas, de acordo com o contexto futebolístico da época, ambos são tributários de pessoas e grupos que, competindo entre si, buscavam se reafirmar dentro de um mesmo universo sociocultural. (DAMO, 2002a, p. 65-66). 
O mesmo autor destaca que os irmãos Poppe, futuros fundadores do Internacional, haviam sido inicialmente barrados em seu pedido de ingresso no Grêmio, devido ao rígido processo exigido aos novos associados, visto que, na busca de preservação de sua identidade, era solicitada uma “[...] espécie de negativa judicial que atestasse a boa índole dos mesmos e, para tanto, dependiam da indicação de sócios mais antigos" (DAMO, 2002a, p. 67). Como recém haviam chegado a Porto Alegre na época, oriundos de São Paulo, não tinham indicações, nem conhecidos ilustres, acabando por não ter êxito em seu projeto de ingressar "[...] no melhor team da capital" (COIMBRA et al., 2009, p. 8). Tal fato fará com que, de acordo com Damo (2002a), os irmãos Poppe juntamente com outras pessoas, decidam pela criação de um novo clube onde pudessem praticar a atividade esportiva.

Dentre as principais questões originárias do Internacional, o fato é que os seus idealizadores “[...] se propuseram, desde logo, a desafiar o Grêmio" (DAMO, 2002a, p. 67). Nesse sentido, Coimbra et al. (2009, p. 9) mencionam a célebre frase do médico, pecuarista e jogador colorado Carlos Kluwe como uma constatação dessa realidade: "Só deixo essa coisa de futebol depois de uma vitória sobre o tal de Grêmio". Formava-se a partir daí a rivalidade Gre-Nal, como destacado por Damo (2002a), ao mencionar que uma vitória se tornara a partir daquele momento uma questão de honra para o Internacional, ao passo que, para o Grêmio, era um fator positivo, visto que havia encontrado finalmente um contendor arrojado. Fundamental alicerce para a consolidação do futebol porto-alegrense, "[...] o Gre-Nal ainda não era GreNal, mas a rivalidade que se iniciava, algo fundamental em se tratando de futebol" (Damo, 2002a, p. 67).

Damo (2002a) contribui ainda para o debate sobre a formatação histórica, já posterior às fundações dos clubes, do contraste entre "clube do povo" e "clube da elite", ao destacar que "[...] ao Inter atribui-se uma série de conotações 'populares' e de 'massa' que, embora precedentes, só haveriam de se configurar nas décadas de 30 e 40” (DAMO, 2002a, p. 64). Já com a implantação do futebol profissional, bem como os novos tipos de públicos que começaram a acompanhar os jogos, principalmente em função dos espaços que os clubes começaram a ganhar nos jornais e rádios, fez com que os clubes se aproximassem de variadas camadas sociais, impossibilitadas de irem aos estádios nas décadas anteriores, possibilitando, também a participação em seus quadros sociais.

Tais conotações "populares" e de "massa" foram ampliadas por basicamente dois motivos no final dos anos 1930 e início dos 1940: o expressivo número de títulos colorados alcançados no período e a autointitulação de "clube do povo", em contraste ao suposto "clube da elite", segundo atesta Damo (2002a). A questão racial contribuiu, também, para reforçar o estigma de "clube do povo" do Internacional, visto que, segundo Gerchmann (2015), foi realizada a partir dos anos 1930 uma grande inclusão de negros no plantel de jogadores colorados, visando buscar maior equilíbrio competitivo com o Grêmio. Assim, a 
inclusão de atletas negros teria se dado por motivos técnicos e não por valores e ideais progressistas. Sobre a questão da técnica apurada dos jogadores negros, Geledés (2000) menciona que:

\begin{abstract}
Nos campos de várzea o jogador negro imprimiu um estilo próprio de magia e arte ao futebol brasileiro, diferente das formas arcaicas do jogo de bola. Os negros jogavam com mais ginga, com mais habilidade e reinventando os espaços, afinal o drible não é outra coisa que a criação de espaço, onde espaço não existe. Foi o que bastou para os clubes grandes realizarem um arrastão nos clubes das Ligas Negras. Contudo, a proibição de escalar jogadores negros criava um problema para técnicos e cartolas. Toda uma seleção de atletas com habilidade, porte físico e vontade de jogar bola ficava de fora dos gramados. Não demorou muito para dirigentes perceberem a vantagem competitiva que teriam caso deixassem ideologias antiquadas de lado e aceitassem atletas negros. (GELEDÉS, 2018, p. 2).
\end{abstract}

Cabe destacar também que, de acordo com Gerchmann (2015), outro fator que colaborou para o processo de inclusão de jogadores negros no Internacional teria sido as dificuldades financeiras enfrentadas pelo clube no período, as quais poderiam ser debeladas com essa atitude, visto que esses jogadores recebiam salários bem mais baixos comparativamente aos brancos. O "esquadrão" colorado conhecido como "Rolo Compressor” foi o grande vencedor do futebol gaúcho dos anos 1940, “[...] composto de muitos jogadores negros de extrema qualidade técnica" (GERCHMANN, 2015, p. 33).

Independente de acontecimentos reais ou versões romanceadas da realidade das primeiras décadas da consolidação de Grêmio e Internacional, conforme se pôde ver nas perspectivas adotadas pelos pesquisadores, o fato é de que o desafio proposto em 1909 pelo noviço clube ao veterano clube acabou por consolidar o futebol em terras gaúchas ao longo do século XX, agora ancorado em uma rivalidade que dividia o estado meio a meio, com base em paixões, dissabores e disputas eternas dentro e fora das quatro linhas. Ainda sobre o desafio proposto pelos precursores colorados, cabe lembrar que o futebol gaúcho se tornou referência para todo o país, visto que “[...] cresceu a ponto de ter dois estádios fantásticos, ultrapassar fronteiras, conquistar títulos continentais e mundiais, contar com milhares de aficionados e ostentar dois dos principais clubes brasileiros" (GERCHMANN, 2015, p. 90).

Merece finalmente lembrar que a antiga, porém permanente, disputa de espaço e poder pela hegemonia do futebol no Rio Grande do Sul por parte dos seus dois grandes clubes, é retroalimentada, eventualmente, pelo discurso do clube popular e democrático contra a agremiação elitista e refratária à inclusão racial. Damo (2002a) tenta concluir o assunto, buscando atualizar a discussão com base em referenciais de um entendimento mais objetivo: 
No caso específico da rivalidade Gre-Nal, o Grêmio tem sido visto como um clube da elite branca e o Internacional como sendo um clube dos populares e dos negros - ambas as imagens são caricatas, mas de qualquer modo recorrentes. Tais vínculos fazem parte da tradição e, como tal, são constitutivos da própria noção de pertencimento. Pouco importa se tais associações são na atualidade incompatíveis com os indicadores socioeconômicos. (DAMO, 2002a, p. 86).

\section{5 "Futebol-arte" X "futebol-força": peculiaridades das expressões gaúchas e brasileiras do jogo de futebol e a relação com o Grêmio e o Internacional}

Uma das discussões mais antigas do futebol gaúcho são as formas tradicionais de praticar esse esporte por seus clubes. Nesse quesito, destaca-se a divisão entre o chamado "futebol-arte" e o "futebolforça". Normalmente, associa-se o Internacional à primeira denominação, e o Grêmio, à segunda, conforme destacado por Damo (2002a) e Tosin (2008).

A tradição gremista de jogar futebol, de acordo com os autores selecionados, é mais acentuadamente vinculada ao longo dos tempos com o "futebol-força", estilo de jogo que se caracterizou como a "forma gaúcha de jogar futebol", que sempre esteve em contraposição à "forma brasileira". O "futebol-força", segundo Lopes (1994), seria aquele em que há o predomínio do preparo e imposição física em detrimento de outras características. Aspectos como a preparação física, relacionados ao condicionamento dos atletas, tendo como base os métodos científicos, estão enraizados nessa forma de pensar o planejamento das equipes de futebol. Dentre os elementos que sustentam esta versão estão, de acordo com Damo (2002a), a influência da tradição germânica originária do clube e o positivismo dominante na época, que acabaram por permear continuamente como valores fundamentais dos jogadores e da equipe a raça, a marcação e o espírito coletivo, dentre outros.

É dessa maneira que, mesmo implicitamente, o estilo gremista aparentemente se encontraria deslocado no cenário brasileiro, visto que, de forma oposta aos padrões impostos pelo denominado "futebolarte", "[...] o sucesso do Grêmio reside na coletividade, no espírito do grupo, na superação, na solidariedade e em outros tantos valores que, se não anulam as individualidades, colocam-nas em segundo plano" (DAMO, 2002a, p. 142). Busca-se, dessa forma, a formatação de uma equipe que alcance os resultados, com base em atletas eficientes e integrados e que, não necessariamente, tenham que ser ótimos jogadores em nível técnico e tático, ainda de acordo com o autor. O coletivo sempre está acima do individual nessa 
lógica empregada comumente também pelas equipes argentinas e uruguaias nas competições internacionais, outra referência para o padrão gaúcho e, mais especificamente, o gremista. Assim:

\begin{abstract}
Nessa perspectiva, o Grêmio era o mais europeu e, por extensão, moderno, e também o mais portenho e, consequentemente, obsoleto dos times brasileiros. Isso não significa que o futebol dos vizinhos uruguaios e argentinos, com os quais os brasileiros rivalizam desde o princípio do século, seja considerado antiquado. O que sempre se diz é que eles são competitivos a ponto de usar dispositivos contrários ao fair-play. E o Grêmio era um exemplo dessa competitividade, por vezes excessiva, incompatível com o futebol-arte que caracteriza a 'tradição' brasileira. (DAMO, 2002a, p. 143).
\end{abstract}

Já o Internacional, de acordo com Tosin (2008), além de ter sido fundado por pessoas de fora do Rio Grande do Sul, teria se apropriado mais rapidamente de um processo de "democratização funcional". Essa conduta proporcionou à elite, mais rapidamente, a possibilidade de deslocamento para a função de administração e controle do clube, ao passo que os jogadores puderam, de forma mais veloz, ser valorizados segundo as suas qualidades técnicas, o que teria feito com que pudessem ascender atletas de distintas origens sociais e raciais.

Pode-se perceber, então, que, nesse mesmo sentido, como no Grêmio, o processo de “democratização funcional” do Internacional foi mais lento, pois determinados aspectos foram cristalizados institucionalmente e, assim, puderam permanecer, justificando a essência identitária do próprio clube ao longo dos períodos posteriores.

Também é comentado por Tosin (2008) que, ao longo das décadas, sempre aconteceu uma maior aproximação do Internacional, comparativamente ao Grêmio, com os órgãos máximos do futebol brasileiro, primeiramente a Confederação Brasileira dos Desportos (CBD), e, depois, com a Confederação Brasileira de Futebol (CBF). Para tanto, destaca-se que as duas Copas do Mundo realizadas no Brasil (1950 e 2014) tiveram como sede os estádios colorados, em terras gaúchas, de acordo com o mesmo autor.

Outro aspecto que validaria este argumento, para o autor, é fato de que a Seleção Brasileira, campeã dos Jogos Pan-Americanos de 1956, era formada exclusivamente por atletas que atuavam no estado do Rio Grande do Sul, majoritariamente colorados. Outro fato foi o "empréstimo" de onze atletas colorados para disputa dos Jogos Olímpicos de 1984, fazendo com que o Internacional se tornasse, naquele momento, “[...] o time da Seleção Brasileira, se confundindo, portanto, com a própria nação” (TOSIN, 2008, p. 40). 
A aceitação maior ao "futebol-arte", paradigma do futebol brasileiro, por parte do Internacional poderia ser vista também nas equipes coloradas vitoriosas ao longo de sua história, quase todas orientadas por treinadores oriundos de outros estados, de acordo com Tosin (2008).

É claro que, como representante do Rio Grande do Sul, percebiam-se elementos do "jogo gaúcho" no Internacional, mas sempre aliados paritariamente à valorização da questão técnica, fato este que pode ter contribuído para que o clube fosse o pioneiro dos clubes gaúchos a alcançar títulos nacionais, ainda na década de 1970. Ainda sobre os técnicos colorados vitoriosos e sua origem, destacado no parágrafo anterior, percebe-se que:

\begin{abstract}
Doravante, quase todos os bons e grandes times que o Internacional formou, contaram com técnicos de fora do Rio Grande do Sul. A formação do bicampeão brasileiro de 1975/1976, começou com Dino Sani e foi finalizada por Rubens Minelli, ambos paulistas; em 1989, na vitória do Gre-Nal do século e chegada nas semifinais da Libertadores da América o time era comandado pelo carioca Abel Braga; o título da Copa do Brasil de 1992 foi vencido pelo Inter sob o comando do também carioca Antonio Lopes; [...] e, por fim, a consagração de 2006 com os títulos da América e Mundial Interclubes se deram com a volta do carioca Abel Braga ao comando. (TOSIN, 2008, p. 41-42).
\end{abstract}

As exceções seriam os gaúchos Ênio Andrade, campeão invicto do Brasileiro de 1979 e, mais recentemente, Adenor Bachi (conhecido como "Tite" e atual técnico da Seleção Brasileira), campeão da Copa Sul-Americana em 2008, e Celso Roth, campeão da Libertadores do ano de 2010, segundo informações do sítio eletrônico do Internacional (2020) e GaúchaZH (2020).

Em linha oposta, os técnicos gremistas vitoriosos foram majoritariamente gaúchos, a começar por Oswaldo Rolla (conhecido como "Foguinho"), responsável por ajudar a vencer doze campeonatos gaúchos em treze anos; Ênio Andrade, campeão brasileiro de 1981; Valdir Espinosa, campeão da Libertadores da América e do Mundial Interclubes de 1983; Cláudio Duarte, campeão da Copa do Brasil em 1989; Luiz Felipe Scolari (conhecido como "Felipão"), pentacampeão do mundo com a Seleção Brasileira em 2002 e campeão da Copa do Brasil de 1994, da Libertadores de 1995 e do Brasileiro de 1996; e, finalmente, Adenor Bachi, campeão da Copa do Brasil de 2001, segundo GaúchaZH (2020) e 90min (2020).

A única exceção foi o fato de que o título da Copa do Brasil do ano de 1997 foi atingido com um carioca no comando da equipe (Evaristo de Macedo). Já com os dados mais recentes, vê-se que Renato Portaluppi, ex-jogador campeão do mundo em 1983, foi outro técnico gaúcho que alcançou títulos 
relevantes: a Copa do Brasil de 2016, a Libertadores de 2017 e a Recopa Sul-Americana de 2018, segundo GaúchaZH (2020) e 90min (2020).

Outro aspecto comentado por Tosin (2008), que refletiria a maior integração colorada com o Brasil, em comparação ao Grêmio, é o próprio hino do clube. O hino colorado, criado pelo carioca Nelson Silva em 1957, faz três menções claramente imbuídas de pertencimento do clube à coletividade nacional, ao destacar citações como "glória do desporto nacional", "vibra o Brasil inteiro" e "orgulho do Brasil", ao passo que somente uma vez se refere ao Rio Grande do Sul, ao mencionar a expressão "clube do povo do Rio Grande do Sul”. Já o hino do Grêmio, datado de 1953 e criado pelo gaúcho Lupicínio Rodrigues, não faz menção alguma à relação do clube com o Brasil, ao mesmo tempo em que se refere uma vez ao estado gaúcho, quando destaca os versos “canta o Rio Grande com amor”.

\section{Conclusão}

Praticado e cultuado no Brasil há mais de um século, o futebol desde cedo foi um elemento da cultura popular no Brasil, representando a apropriação e integração de diferentes classes sociais, tanto na arquibancada, gestão dos clubes e dentro das "quatro linhas", quanto nas mesas de bares e outros locais de reuniões populares, em que era o assunto principal.

Foi por esse motivo que, ao longo das últimas décadas, com as discussões sobre os elementos históricos e constitutivos das representações de Grêmio e Internacional, esses clubes, já então consolidados como rivais permanentes, permearam o imaginário do torcedor gaúcho, que tem como base os dois clubes, fomentando assim a formação de enredos sociais que, de tempos em tempos, vai sendo rememorado, mesmo que muitas vezes não se mostre como efetivamente correto. Nesse sentido, merece papel importante a midiatização das notícias e debates sobre o Internacional e Grêmio, com base em sua rivalidade, fomentada na apresentação aos seus públicos - no caso, torcedores - em diferentes plataformas, como o jornal, a televisão e o rádio, bem como, mais recentemente, as mídias eletrônicas.

No que se refere às ditas origens populares ou elitistas dos clubes, muitas questões podem ser destacadas para tentar justificar determinadas perspectivas, todas ancoradas em elementos que mostram os primórdios da fundação clubística, o contexto social da época, a busca de afirmação social dos diferentes indivíduos e a ideia de que um clube já nasce originalmente em oposição ao outro. Com o passar das primeiras décadas, novos elementos foram sendo colocados no "caldeirão" do imaginário que estava se 
formando e, desde já, se consolidando, mesmo que não fossem elementos que encerrassem a discussão, visto a perspectiva multifacetada das análises.

A hegemonia colorada nas décadas de 1930 e 1940 também foi um aspecto que amplificou tal processo, o que teria servido, de acordo com algumas versões, para o aumento do próprio número de torcedores colorados no período, ainda mais na fase de instauração do profissionalismo do futebol gaúcho e brasileiro. Foi nesse momento que a imagem de "clube do povo" por parte do Internacional teria se efetivado, fazendo com que, se este fosse o clube das classes populares, seu rival somente poderia ser o clube associado às classes ricas.

Relativamente ao estilo de jogo praticado historicamente, as origens clubísticas também podem ser retomadas, em que a questão relacionada a uma possível democratização funcional mais rapidamente ocorrida no Internacional teria sido um dos fatores que fez com que o clube adotasse o "estilo brasileiro". Enquanto isso, seu rival teria adotado o "estilo gaúcho", por causa de suas relações embrionárias com os imigrantes alemães, por ter sofrido maior influência dos valores positivistas vigentes na época e pelo próprio futebol praticado nos países fronteiriços.

Tais elementos parecem se confirmar na formação dos clubes vitoriosos ao longo da sua história, marcadamente quando se observam as conquistas nacionais e internacionais que aconteceram para o Grêmio, com técnicos gaúchos, e para o Internacional com técnicos de outros estados. Também deve ser percebido que os próprios hinos dos clubes fazem menções ao sentimento de brasilidade ou regionalidade de forma diferenciada, atribuindo maior importância a um em detrimento do outro.

Entretanto, a discussão não pode ser considerada como encerrada, visto que toda pesquisa social pode ser vista por diferentes nuances que podem reforçar ou não determinados elementos, enquanto pode esquecer outros. Além disso, deve-se ter em conta que as perspectivas da percepção da prioridade de um estilo de jogo, em detrimento de outro, por exemplo, é também um elemento do imaginário do torcedor, o que faz com que, não necessariamente, a realidade dos diferentes processos acontecidos dentro de campo sejam relacionados ao que se pensa ou ao que se acredita pensar, ainda mais considerando a linearidade histórica dos acontecimentos.

Finalmente, nota-se também a consolidação da rivalidade entre Internacional e Grêmio com base em seus enfrentamentos históricos e na busca de superação ao outro nos campeonatos disputados. Essa característica faz com que as diferenças entre os elementos abordados não sejam apresentadas de uma maneira que confirme objetivamente tais realidades, sendo objeto mais de um debate relacionado à tradição, com base no pertencimento clubístico, do que a qualquer outra coisa. 
Tal aspecto poderia ser facilmente visto, por exemplo, em pesquisa recente que mostra a superioridade da torcida do Grêmio comparativamente à do Internacional, em aspectos como o número total de torcedores, seu predomínio em todas as classes sociais e nas diferentes regiões do Rio Grande do Sul, de acordo com GaúchaZH (2018). Segundo a série histórica, observa-se, em suas últimas 23 (vinte e três) edições da mesma pesquisa, o predomínio gremista enquanto o clube de futebol mais lembrado no Rio Grande do Sul. Tratar-se-ia, então, de um novo "clube do povo"?

\section{Referências}

90min. Os 5 maiores treinadores da história do Grêmio. 2020. Disponível em: < https://www.90min.com/pt-BR/posts/6600103-os-5-maiores-tecnicos-da-historia-do-gremio $>$. Acesso em: 24 jul. 2020.

BIAGI, M. C. Pesquisa Científica: roteiro prático para desenvolver projetos e teses. Curitiba: Juruá, 2012.

BRAGA, K. Inter 90 anos de paixão. Porto Alegre: Já Editores, 2000.

COIMBRA, D. et al. A história dos grenais. Porto Alegre: L\&PM, 2009.

COMTE, A. Curso de filosofia Positiva. Seleção de textos de J. A. Giannotti. São Paulo: Abril Cultural, 1978.

DA MATTA, R. et al. O universo do futebol: esporte e sociedade brasileira. Rio de Janeiro: Pinakotheke, 1982.

DAMO, A. S. Futebol e identidade social: uma leitura antropológica das rivalidades entre torcedores e clubes. Porto Alegre: Ed. Universidade/UFRGS, 2002a.

Excertos de história social do futebol gaúcho e sua especificidade em relação ao Brasil. Verso \& Reverso. São Leopoldo: Ed. UNISINOS, ano XVI, n. 34, 2002 b.

DESCHAMPS, J. C.; MOLINER, P. A identidade em Psicologia Social: dos processos identitários às representações sociais. 2. ed. Petrópolis/RJ: Vozes, 2014.

FERLA, M. C. O imortal tricolor. Porto Alegre: L\&PM, 2002.

FRANCO Jr., H. A dança dos deuses: futebol, cultura, sociedade. São Paulo: Companhia das Letras, 2007.

GAÚCHAZH. Esportes. Treinadores que venceram títulos por Grêmio e Inter. 2020. Disponível em: < https://gauchazh.clicrbs.com.br/esportes/noticia/2020/05/treinadores-que-venceram-titulos-por-gremio-einter-cka3tnteu0018015nxko4mliq.html >. Acesso em: 24 jul. 2020.

Esportes. Grêmio supera o Inter no Top of Mind em todas as classes sociais e regiões

pesquisadas. 2018.

Disponível

em:

https://gauchazh.clicrbs.com.br/esportes/gremio/noticia/2018/05/gremio-supera-o-inter-no-top-of-mindem-todas-as-classes-sociais-e-regioes-pesquisadas cjgz624hy03m301paopwwxnpk.html > Acesso em: 05 mar. 2019. 
GELEDÉS Instituto da Mulher Negra. Artigos e Reflexões. O negro no futebol brasileiro: inserção e racismo. 2018. Disponível em: < https://www.geledes.org.br/o-negro-no-futebol-brasileiro-insercao-e-

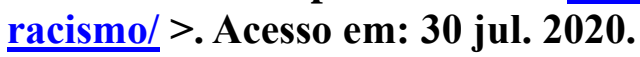

GERCHMANN, L. Somos azuis, pretos e brancos. Porto Alegre, RS: L\&PM, 2015.

GIL, A. C. Métodos e técnicas de pesquisa social. 6. ed. São Paulo: Atlas, 2014.

GOFFMAN, E. A representação do eu na vida cotidiana; tradução de Maria Célia Santos Raposo. Petrópolis: Vozes, 1985.

GUAZZELLI, C. A. B. Futebol em tempos de ditadura: o Rio Grande do Sul contra o Brasil. Aurora: revista de arte, mídia e política. n. 9, 2010.

LOPES, J. S. L. A vitória do futebol que incorporou a pelada: a invenção do jornalismo esportivo e a entrada dos negros no futebol brasileiro. Revista USP. São Paulo, n. 22, 1994, p. 64-83.

SPORT CLUB INTERNACIONAL. História do clube. 2020. Disponível em: < https://www.internacional.com.br/historia/historia > Acesso em: 25 jul. 2020.

TOSIN, M. Futebol e identidade: entre o estado e a nação. IFCH, Departamento de História (TCC: Bacharel em História), UFRGS, Porto Alegre, 2008.

WOODWARD, K. Identidade e diferença: uma introdução teórica e conceitual. In: SILVA, T. T. da. Identidade e diferença: a perspectiva dos estudos culturais. 14. ed. Petrópolis, RJ: Vozes, 2014.

\section{Como citar este artigo}

TRICHES, V.; ZAT, A. D. O. As representações históricas e constitutivas de Internacional e Grêmio no futebol gaúcho e seus enredos sociais. Revista Kinesis, Santa Maria, v. 39, p.01-16, 2021.

* O presente trabalho não contou com apoio financeiro de nenhuma natureza para sua realização. 